\title{
Pengembangan Flipped classroom Untuk Mata Kuliah Belajar Berbasis Komputer Di Universitas Negeri Jakarta
}

\author{
Zara Larasati, ${ }^{\otimes}$ Cecep Kustandi ${ }^{2}$, Kunto Imbar Nursetyo ${ }^{2}$ \\ ${ }^{1}$ Universitas Negeri Jakarta, Jakarta, Indonesia. \\ ${ }^{2}$ Universitas Negeri Jakarta, Jakarta, Indonesia. \\ 3 Universitas Negeri Jakarta, Jakarta, Indonesia.
}

DOI: https://doi.org/10.21009/JPI.022.o6

\begin{tabular}{l}
\hline Article History \\
\hline Received : 2019 \\
Accepted : 2019 \\
Published : 2019 \\
\hline Keywords \\
\hline flipped classroom; \\
elearning; course site; \\
belajar berbasis \\
komputer; rapid \\
prototype
\end{tabular}

Received : 2019

Accepted : 2019

flipped classroom; belajar berbasis

komputer; rapid prototype

\begin{abstract}
Abstrak
Penelitian pengembangan ini bertujuan menghasilkan pembelajaran flipped classroom di perguruan tinggi pada umumnya dan dikhususkan pada mata kuliah belajar berbasis komputer. Produk yang dikembangkan antara lain: silabus perkuliahan, panduan, dan course site. Sasaran dari penelitian ini ialah dosen mata kuliah belajar berbasis komputer dan mahasiswa teknologi pendidikan semester pertama. Penelitian pengembangan ini menggunakan model pengembangan rapid prototype yang memiliki lima tahapan yakn assess needs $\mathcal{E}$ analyze content, set objectives, construct prototype, utilize prototype, install $\mathcal{E}$ maintain system. Evaluasi pada penelitian ini dilaksanakan melalui expert review, yaitu ahli desain pembelajaran, ahli materi, dan ahli media. Nilai rata-rata yang diperoleh dari ahli desain pembelajaran ialah 3,7. Nilai rata-rata yang diperoleh dari ahli materi ialah 3,8. Nilai rata-rata yang diperoleh dari ahli media ialah 3,3. Melalui ketiga evaluasi yang telah dilaksanakan dapat disimpulkan bahwa pengembangan pembelajaran flipped classroom untuk mata kuliah belajar berbasis komputer ini sudah sangat baik dan dapat digunakan oleh dosen.
\end{abstract}

\begin{abstract}
This development research aims to produce flipped classroom learning in universities generally, especially to computer-based learning courses. Products development included lecture syllabus, guide and course site. The objectives of this study were computer-based study lecturers and first year of educational technology students. This research development is used as a rapid prototype development model that has five stages, namely assess needs $\mathcal{E}$ analyze content, set objectives, construct prototype, utilize prototype, install and maintain system. The evaluation in this study was carried out through expert reviews, namely learning design experts, material experts, and media experts. The average value obtained from learning design expert is 3.7. The average value obtained from material experts is 3.8. The average value obtained form of media experts is 3.3. Through the three evaluations that have been carried out, it can be summarized that the development of flipped classroom learning for computer-based learning courses has been very good and can be utilized by lecturers
\end{abstract}




\section{PENDAHULUAN}

Teknologi pendidikan merupakan salah satu program studi yang terdapat di bawah naungan fakultas ilmu pendidikan, universitas negeri pendidikan. Menurut AECT (2004) teknologi pendidikan memiliki definisi sebagai berikut:

Educational technology is the study and ethical practice of facilitating learning and improving performance by creating, using, and managing appropriate technological processes and resources.

Jika dibahasakan, dapat diartikan bahwa teknologi pendidikan adalah studi dan praktek etis dalam upaya menfasiliasi pembelajaran dan meningkatkan kinerja dengan cara menciptakan, menggunakan/memanfaatkan, dan mengelola proses dan sumber-smber teknologi yang tepat. Jelas, tujuan utamanya masih tetap untuk menfasilitasi pembelajaran (agar efektif, efisien, dan menarik) dan meningkatkan kinerja. Pembelajaran dalam program studi ini pun selalu berubah mengikuti zaman dan teknologi. Dalam pembelajarannya kini, program studi ini memiliki 2 (dua) konsentrasi, yaitu teknologi kinerja dan desainer pembelajaran. Padahal dulu, pada tahun 2016 ke bawah, program studi teknologi pendidikan memiliki 3 (tiga) konsentrasi, yaitu teknologi kinerja, desainer pembelajaran, dan media.

Perubahan ini membawa banyak dampak pada mata kuliah yang tersedia di program studi ini. Salah satunya adalah pada mata kuliah belajar berbasis komputer (BBK). Mata kuliah belajar bebasis komputer sebelumnya merupakan mata kuliah prasyarat yang dapat dipelajari oleh mahasiswa ketika sudah berada di semester 4. Agar dapat mengambil mata kuliah ini, peserta didik wajib sudah pernah mengambil mata kuliah pengenalan komputer. Namun, karena perubahan kurikulum yang telah dijelaskan sebelumnya, sekarang mata kuliah BBK ini berubah menjadi mata kuliah yang wajib untuk dipelajari oleh seluruh mahasiswa teknologi pendidikan di semester 1 perkuliahannya.
Dikarenakan perubahan kebutuhan belajar peserta didik dan perubahan sasaran dalam mata kuliah BBK ini, maka pengembang terdorong untuk mengembangkan pembelajaran dengan model flipped classroom pada mata kuliah belajar berbasis komputer. model flipped classroom merupakan Herala, Vanhala, Knutas, \& Inkonen (2016) bahwa Flipped Classroom adalah model dimana peserta didik pertama belajar dengan teori bebas di luar kelas dan kemudian berlatih di kelas dengan bimbingan dari guru.

Menurut Derek Bruff dan Vanderbilt (2016), ada beberapa perbedaan antara model pembelajaran konvensional dengan Flipped Classroom. Antara lain:

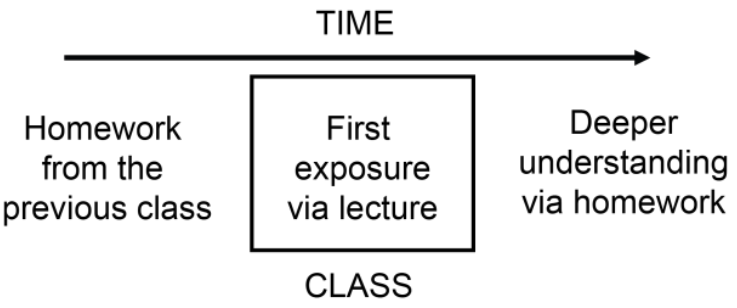

Gambar 1. Model pembelajaran Konvensional

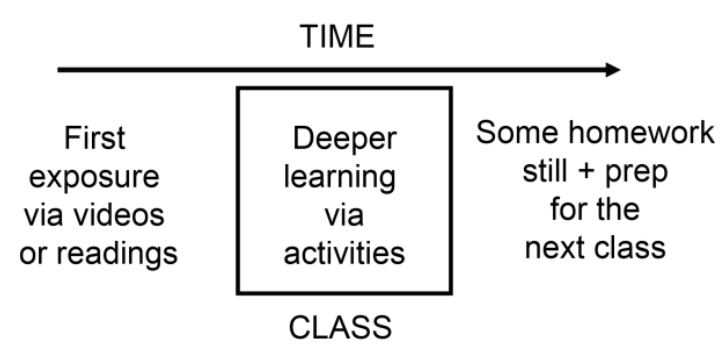

Gambar 2. Model pembelajaran Flipped Classroom

Berdasarkan gambar diatas, dapat disimpulkan bahwa Flipped Classroom adalah salah satu model pembelajaran dimana peserta didik terlebih dahulu belajar mandiri dengan menggunakan sumber belajar yang diberikan oleh guru di luar kelas sebelum materi dijelaskan. Hal ini bertujuan supaya peserta didik dapat memperoleh pengetahuan yang diperlukan sebelum pelajaran di kelas dan selama di kelas guru dapat membimbing peserta didik agar lebih aktif dan interaktif dalam proses belajar. Serta guru mempunyai lebih banyak waktu untuk menjelaskan atau menyelesaikan masalah yang ditemukan para peserta didik. 
Untuk menemukan kebutuhan belajar, karakteristik peserta didik, dan lingkungan pembelajaran, pengembang sekaligus peneliti telah melaksanakan beberapa analisis kebutuhan dan analisis materi. Pencarian data yang dilaksanakan menggunakan beberapa metode, antara lain wawancara dengan dosen pengampu dan penyebaran kuisioner yang diisi oleh mahasiswa teknologi pendidikan yang telah mempelajari mata kuliah ini.

Berdasarkan data analisis kebutuhan dan analisis materi yang telah diperoleh menunjukkan bahwa; 1) mata kuliah BBK diharapkan dapat menjadi mata kuliah dasar untuk mahasiswa agar dapat memiliki kemampuan untuk memanfaatkan komputer dan teknologi dalam pembelajaran. 2) karakteristik peserta didik yang akan mempelajari mata kuliah BBK ini termasuk ke dalam generasi digital native. Mark Prensky (2001) menyatakan digital native merupakan gambaran seseorang (terutama anak hingga remaja) yang sejak kelahirannya telah terpapar gencarnya perkembangan teknologi. 3) terbatasnya durasi pembelajaran mata kuliah BBK menyebabkan peserta didik tidak dapat mempelajari materi terlalu dalam. 4) mata kuliah BBK belum berintegrasi dengan system pembelajaran daring.

Penelitian serupa juga pernah dilaksanakan oleh Nouri (2016) yang menyatakan bahwa peserta didik memberikan respon positif terhadap flipped classroom. Dikarenakan mereka mengalami peningkatan motivasi, belajar, belajar lebih efektif dan peningkatan belajar setelah menggunakan model flipped classroom.

Pengembangan ini penting dilaksanakan karena banyaknya kebutuhan belajar peserta didik yang harus dipenuhi demi mencapai tujuan pembelajaran dan durasi perkuliahan mata kuliah BBK yang sedikit menuntut pentingnya pengembangan flipped classroom ini. Dengan dikembangkannya flipped classroom ini diharapkan pembelajaran mata kuliah BBK dapat lebih mudah untuk mencapai tujuan pembelajarannya.

Artikel ini menguraikan proses pengembangan flipped classroom untuk mata kuliah belajar berbass komputer di universitas negeri Jakarta. Pengembangan ini diharpkan dapat berguna secara teoritis karena menjelaskan mengenai proses pengembangan flipped classroom di sebuah perguruan tinggi, serta dapat pula dijadikan referensi bagi pengembang serupa agar terlaksana dengan lebih baik dan mendalam. Selain itu, hasil produk pengembangan ini yang berupa silabus perkuliahan, panduan pembelajaran, dan course site diharapkan dapat digunakan oleh dosen terkait untuk menfasilitasi belajar peserta didik dan menjadi asset lembaga yakni dokumentasi pengetahuan mengenai flipped classroom.

\section{METODE}

Penelitian ini merupakan penelitian pengembangan yang menggunakan model pengembangan rapid prototype. Model pengembangan rapid prototype terdiri dari lima tahapan besar, yaitu: assess needs $\mathcal{E}$ analyze content, set objectives, construct prototype, utilize prototype, dan install $\mathcal{E}$ maintain system.

Penelitian ini dilaksanakan di program studi Teknologi Pendidikan, Fakultas Ilmu Pendidikan, Universitas Negeri Jakarta (FIP UNJ). Adapun durasi penelitian dilakukan selama 7 bulan dimulai dari bulan febuari hingga juli 2019, dengan sasaran penelitian yaitu dosen mata kuliah BBK dan mahasiswa

Teknologi Pendidikan angkatan 2019.

Pengembangan flipped classroom ini melibatkan satu orang ahli desain pembelajaran, satu orang ahli materi, dan satu orang ahli media. Teknik evaluasi yang digunakan ialah expert review. Pada tahap evaluasi, digunakan kuesioner sebagai instrument penelitian. Kuesioner yang dibuat menggunakan skala 1-4 untuk menilai aspekaspek sebagai berikut: 1) desain pembelajaran, 2) course site, 3) tampilan muka/interface, 4) learning object, 5) bahasa, 6) aspek pembelajaran, 7) konten, 8) penyajian, 9) navigasi, 10) media pendukung. Untuk mengolah data yang diperoleh melalui kuesioner, menggunakan teknik analisis data dengan rumus statistic sederhana untuk mengetahui skor rata-rata 
yang selanjutnya dianalisis secara deskriptif untuk mengambil kesimpulan.

\section{HASIL DAN PEMBAHASAN}

Pengembangan flipped classroom ini dilaksanakan melalui lima tahap sesuai dengan model pengembangan flipped classroom (2016), dengan penjabaran sebagai berikut:

\section{A. Assess needs $\mathcal{E}$ analyse content}

Pada tahap ini pengembang melakukan assess needs $\mathcal{E}$ analyze content dengan melakukan wawancara dengan dosen pengampu mata kuliah BBK dan menyebarkan kuisioner kepada mahasiswa teknologi pendidikan. Adapun hasil yang diperoleh dari assess needs $\mathcal{E}$ analyze content ini ialah:

Tabel 1 Hasil assess needs $\mathcal{E}$ analyse content

\begin{tabular}{clll}
\hline No & Aspek & \multicolumn{2}{l}{ Deskripsi } \\
\hline 1. & Materi & Materi pembelajaran \\
& pembelajaran & masih menggunakan \\
& & materi yang lama \\
& & sehingga peserta didik \\
& & tidak paham \& dujuan \\
& & mengerti di mata \\
& & pembelajaran di tersebut. \\
\hline
\end{tabular}

\begin{tabular}{lll}
\hline 2. & Durasi & Durasi penyampaian \\
pembelajaran & pembelajaran terbatas \\
& dan beberapa materi \\
& tidak bisa diperlajari \\
& terlalu dalam karena \\
& terbatasnya waktu \\
& pembelajaran. \\
& Peserta didik yang akan \\
& mempelajari mata \\
& kuliah BBK merupakan \\
& generasi digital natives \\
& yang memiliki gaya \\
& belajar visual. \\
& Materi yang didik & dibutuhkan dalam mata \\
& kuliah ini adalah \\
& penulisan akademik, \\
& presentasi zen, search \\
& engine, etika \\
& berkomunikasi, trend \\
Materi & teknologi, dan literasi \\
& perangkat lunak. \\
\hline 4. &
\end{tabular}

\section{B. Set objectives}

Selanjutnya pengembang mulai menentukan tujuan pembelajaran. Adapun tujuan pembelajaran mata kuliah belajar berbasis komputer yang dikembangkan terdapat pada gambar 1 .

Setelah menentukan ke-8 (delapan) capaian pembelajaran ini, maka pengembang mulai mengembangkan strategi pembelajaran Flipped Classroom. Tahapan selanjutnya yang akan

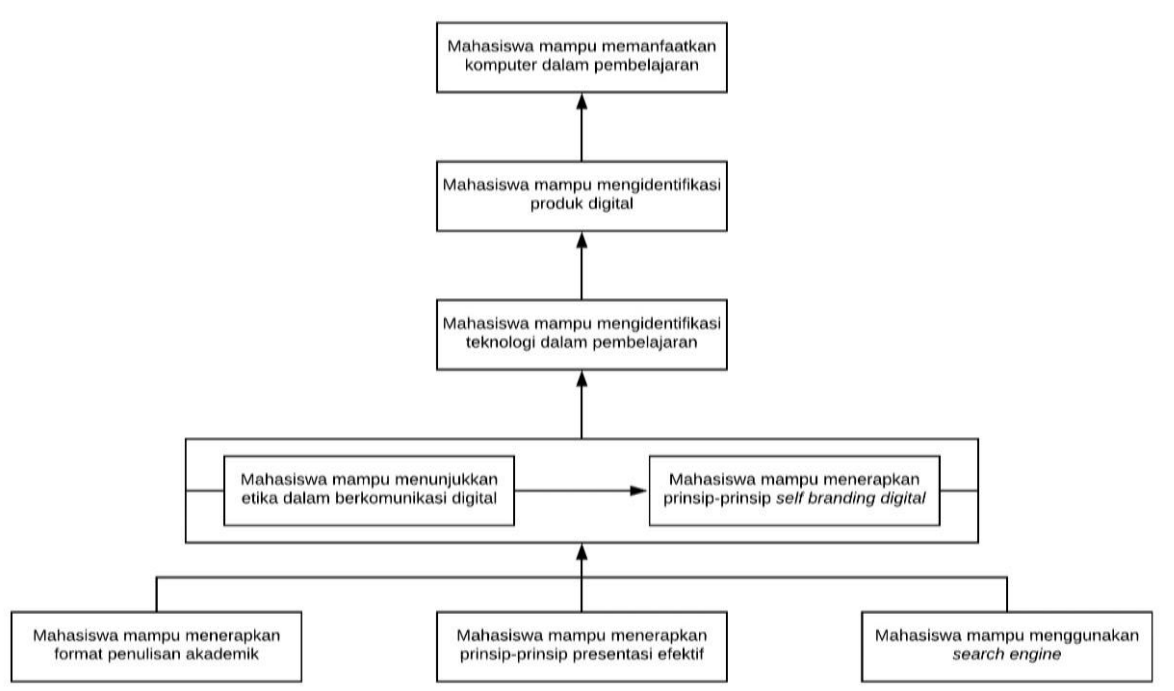

Gambar 3 Tujuan pembelajaran mata kuliah BBK 
dilaksanakan oleh pengembang adalah Construct Prototype

\section{Construct prototype}

Dalam tahap ketiga dalam pengembangan ini, pengembang mulai merancang pembelajaran flipped classroom untuk mata kuliah belajar berbasis komputer. adapun rancangan yang dilakukan oleh pengembang ialah: 1) memetakan materi dan mengorganisasikan setting pembelajaran, 2) merancang aktivitas pembelajaran asinkron, 3) merangkai alur pembelajaran asinkron, 4) merancang aktivitas pembelajaran sinkron langsung, 5) merancang alur pembelajaran sinkron langsung, 6) mengembangkan dan menyiapkan learning object, dalam mengembangkan LO pengembang menggunakan bantuan software Powerpoint, sedangkan dalam memanfaatkan LO pengembang memanfaatkan web site youtube dan platform Slideshare, 7) mengembangkan tes formatif yang mendukung capaian pembelajaran, 8), mengembangkan learning guide, 9) menyusun silabus perkuliahan berdasarkan tujuan pembelajaran mata kuliah, 10) mengembangkan course site pada platform e-learning di http://fip.unj.ac.id/hylearn/, mengembangkan instrument evaluasi expert review.

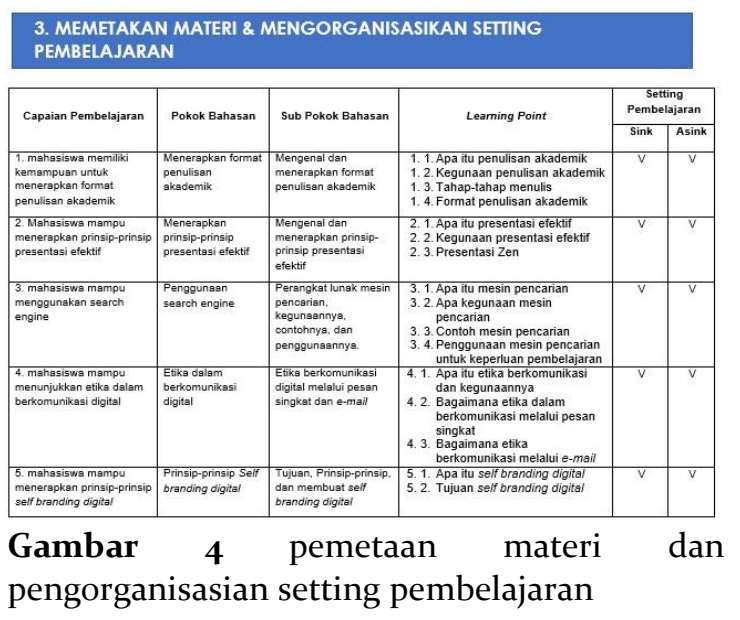

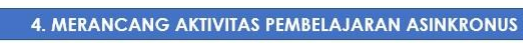

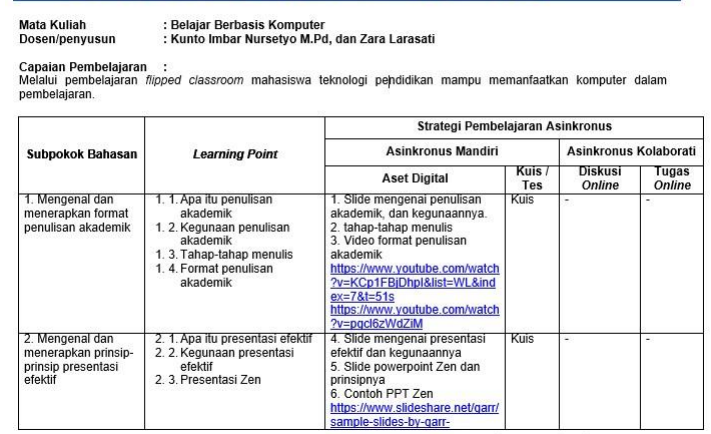

Gambar 5 rancangan pembelajaran asinkron

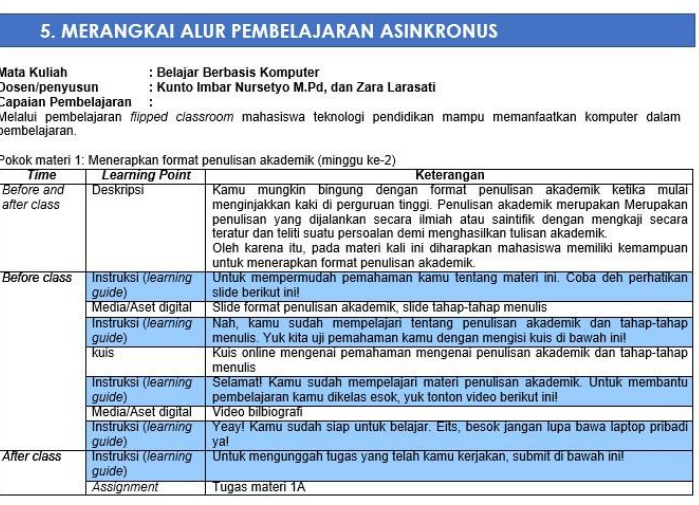

Gambar 6 rancangan alur pembelajaran asinkron

\section{MERANCANG AKIIVITAS PEMBELAJARAN SINGKRON LANGSUNG}

\section{$\begin{array}{ll}\text { Mata Kuliah } & : \text { Belajar Berbasis Komputer } \\ \text { Dosen/penyusun } & : \text { Kunto Imbar Nursetyo M.Pd, dan Zara Larasati }\end{array}$}

Capaian Pembelajaran :
Melauli pembelajaran ffipped classroom mahasiswa teknologi pendidikan mampu memanfaatkan komputer dalam
pembelajaran

\begin{tabular}{|c|c|c|c|c|}
\hline Subpokok Bahasan & Learning Point & Metode & Media & Asesmen \\
\hline $\begin{array}{l}\text { 1. Mengenal dan } \\
\text { menerapkan format } \\
\text { penulisan akademik }\end{array}$ & $\begin{array}{l}\text { 1.1. Words dasar biblografil } \\
\text { 1.2 Words dasar heading dan } \\
\text { daftar isi }\end{array}$ & $\begin{array}{l}\text { The Whole Class } \\
\text { Model }\end{array}$ & \begin{tabular}{|l} 
Video format \\
penulisan akademik
\end{tabular} & Praktek \\
\hline $\begin{array}{l}\text { 2. Mengenal dan } \\
\text { menerapkan prinsip- } \\
\text { pinsip resentasi- } \\
\text { efektip }\end{array}$ & 2.1 Powerpoint Zen & $\begin{array}{l}\text { The Whole Class } \\
\text { Model }\end{array}$ & $\begin{array}{l}\text { Slide contt } \\
\text { Zen }\end{array}$ & Praktek \\
\hline $\begin{array}{l}\text { 3. Perangkat lunak } \\
\text { mesin pencarian, } \\
\text { kegunaannyaa, } \\
\text { contonnyya, dan } \\
\text { penggunaannya. }\end{array}$ & $\begin{array}{l}\text { 3.1 Penggunaan mesin } \\
\text { pencarian untuk } \\
\text { keperiuan pembelajaran }\end{array}$ & The Carousel Model & $\begin{array}{l}\text { Slide mengenai } \\
\text { mesin pencarian dan } \\
\text { contohnya }\end{array}$ & Pemaparan \\
\hline $\begin{array}{l}\text { 4. Etiga berkomunikasi } \\
\text { dipitala melalulu pesan } \\
\text { singkat dan } \mathrm{\theta} \text {-mail }\end{array}$ & 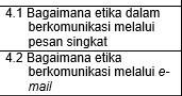 & $\begin{array}{l}\text { The Whole Class } \\
\text { Model }\end{array}$ & $\begin{array}{l}\begin{array}{l}\text { Format berkomukasi } \\
\text { melalui peskan } \\
\text { singkat } \\
\text { Fomati } \\
\text { berkomunikikasi } \\
\text { melalulue e-mail }\end{array} \\
\end{array}$ & Penerap \\
\hline
\end{tabular}

Gambar 7 rancangan aktivitas pembelajaran sinkron langsung 


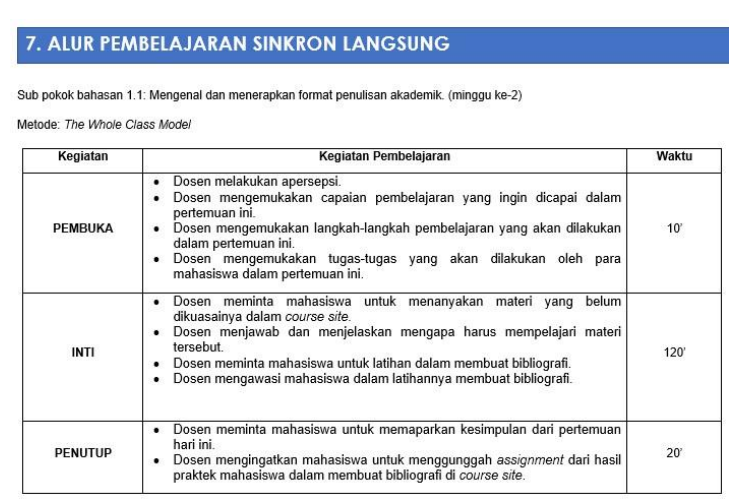

Gambar 8 rancangan alur pembelajaran sinkron langsung

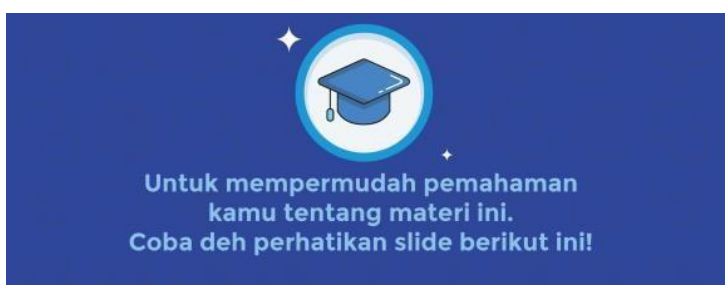

Gambar 9 learning guide yang telah dikembangkan

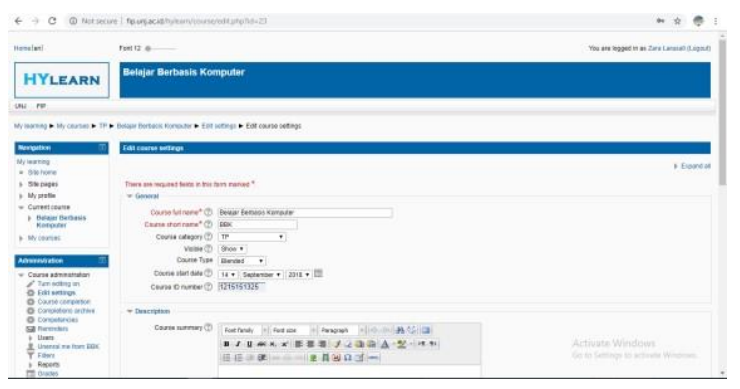

Gambar 10 mengembangkan course site pada platform http://fip.unj.ac.id/hylearn/

\section{Utilize prototype}

Tahap selanjutnya ialah mengevaluasi produk yang telah dikembangkan, untuk mengevaluasi pengembangan flipped classroom ini, dilaksanakan oleh 3 orang ahli yakni ahli desain pembelajaran, ahli materi, dan ahli media.

Tabel 2 Rekapitulasi expert review

\begin{tabular}{lc}
\hline \multicolumn{1}{c}{ Responden } & Nilai rata-rata \\
\hline Ahli desain pembelajaran & 3,7 \\
\hline Ahli materi & 3,8 \\
\hline
\end{tabular}

\begin{tabular}{cc}
\hline Ahli media & 3,3 \\
\hline Rata-rata keseluruhan & $\mathbf{3 , 6}$ \\
\hline Berdasarkan hasil penghitungan serta
\end{tabular}
acuan penilaian dengan skala yang digunakan adalah skala 1-4 yang berarti:

1. Nilai 3,26-4= sangat baik

2. Nilai 2,51-3-25 = baik

3. Nilai $1,76-2,5=$ buruk

4. Nilai 1-1,75 = sangat buruk

Maka, nilai yang diperoleh dari ahli desain pembelajaran sebesar 3,7 masuk ke dalam kategori "sangat baik", lalu nilai yang di peroleh dari ahli materi sebesar 3,8 masuk ke dalam kategori "sangat baik", dan nilai yang diperoleh dari ahli media sebesar 3,3 masuk ke dalam ketegori "sangat baik". Maka hasil nilai rata-rata keseluruhan yang dicapai adalah sangat baik, dengan nilai rata-rata keseluruhan sebesar 3,6. Oleh karena itu, pengembangan flipped classroom yang dilaksanakan dapat disebut telah memiliki kualitas yang sangat baik dari aspek desain pembelajaran, materi, maupun media. Namun ada beberapa masukan dari ketiga ahli tersebut untuk perbaikan flipped classroom, seperti halnya tersaji dalam tabel 3 di bawah ini:

Tabel 3 Rekapitulasi saran dan revisi expert review

\begin{tabular}{cll}
\hline Responden & Saran & Perbaikan \\
\hline Ahli desain & Petunjuk & Akan dibuat \\
pembelajaran & penggunaa & panduan \\
& n /jadwal & pembelajaran \\
& antara tatap & Flipped \\
muka & classroom yang \\
& ditampilkan & dapat \\
& saja ya. & dibagikan \\
& & secara softcopy \\
& & kepada peserta \\
& & didik agar \\
& & mudah melihat \\
& & jadwal antara \\
& & tatap muka \\
& & dan online. \\
& & $\begin{array}{l}\text { Akan diperjelas } \\
\text { metode yang }\end{array}$ \\
& Perjelas & digunakan \\
& metode saat & saat alur \\
& sinkron. & pembelajaran \\
& & sinkron. \\
\hline
\end{tabular}




$\begin{array}{ll}\text { Perjelas } & \text { Akan diperjelas } \\ \text { kegiatan } & \text { kegiatan } \\ \text { belajar/ } & \text { belajar/materi } \\ \text { materi } & \text { yang dibahas } \\ \text { sinkron } & \text { saat alur } \\ & \text { pembelajaran } \\ & \text { sinkron. }\end{array}$

\begin{tabular}{lll}
\hline Ahli media & Sebagai & Akan dibuat \\
media & panduan \\
untuk & pembelajaran \\
& Flipped & Flipped \\
Classroom, & classroom yang \\
materi & dapat \\
kurang & dibagikan \\
kaya, & secara softcopy \\
learning & kepada peserta \\
guidance & didik agar \\
kurang & mudah melihat \\
menunjukk & jadwal antara \\
an ke- & tatap muka \\
flipped- & dan online. \\
annya. & \\
Cek typo, & Akan kembali \\
cukup & diperbaiki tata \\
banyak & penulisan dari \\
& produk yang \\
& telah \\
& dihasilkan. \\
& \\
&
\end{tabular}

\section{E. Install \& maintain system}

Tahapan selanjutnya adalah install $\mathcal{E}$ maintain system, pada tahapan ini pengembang melakukan revisi dari saran yang diberikan pada tahapan sebelumnya. Adapun hal-hal yang dilaksanakan pada tahapan install $\mathcal{E}$ maintain system ini, antara lain: a) perbaikan ulang dan penambahan saran pada produk berdasarkan hasil penilaian oleh para ahli, b) menggunggah learning object yang telah diperbaiki ulang dan menyusun learning guide dalam course site.

Mengacu pada data-data diatas, maka penelitian ini menghasilkan beberapa produk. Antara lain: 1) silabus perkuliahan, 2) panduan pembelajaran, dan 3) Course site untuk mata kuliah belajar berbasis komputer

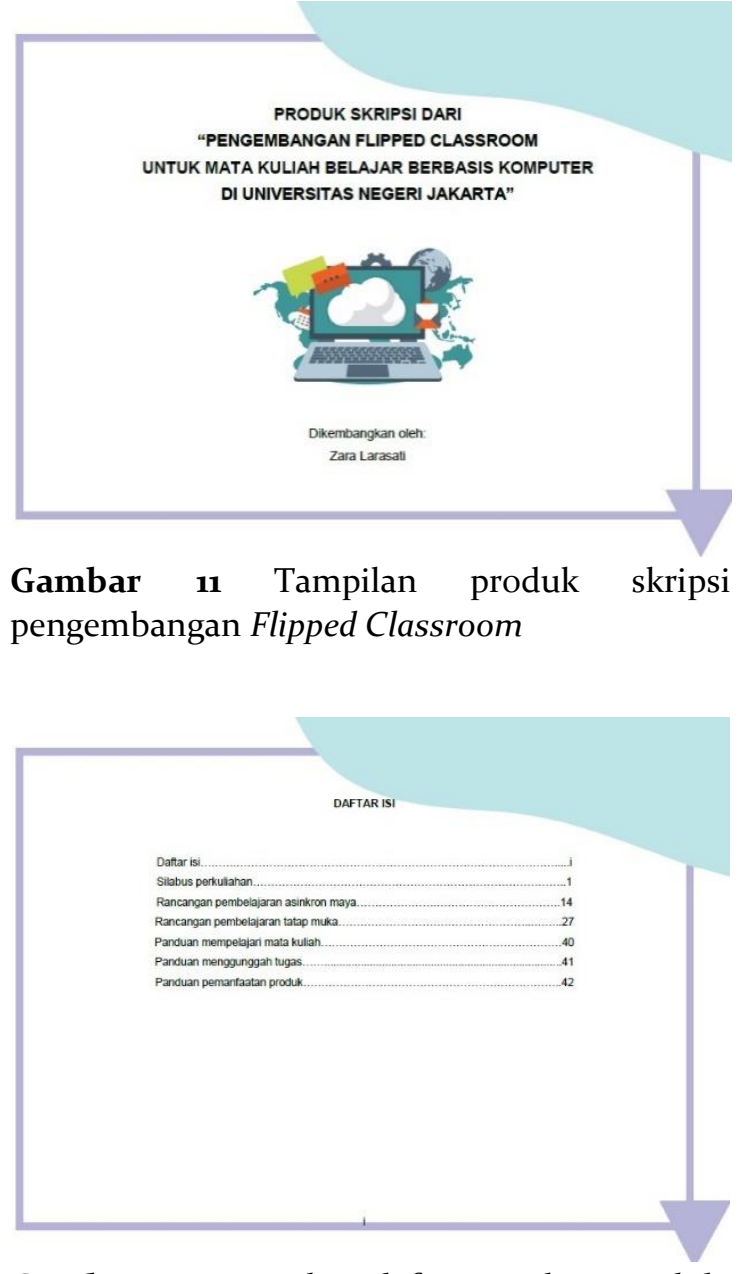

Gambar 12 Tampilan daftar isi dari produk skripsi pengembangan Flipped Classroom

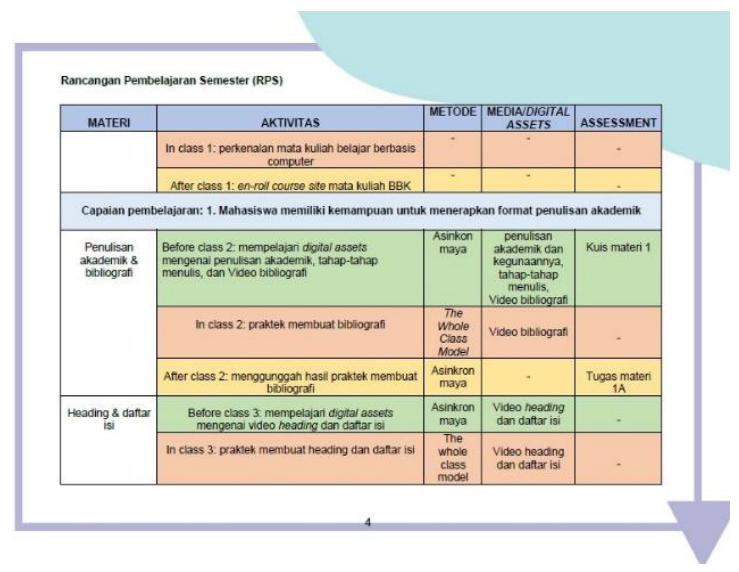

Gambar 13 Tampilan Rancangan Pembelajaran Semester pada produk skripsi pengembangan Flipped Classroom 


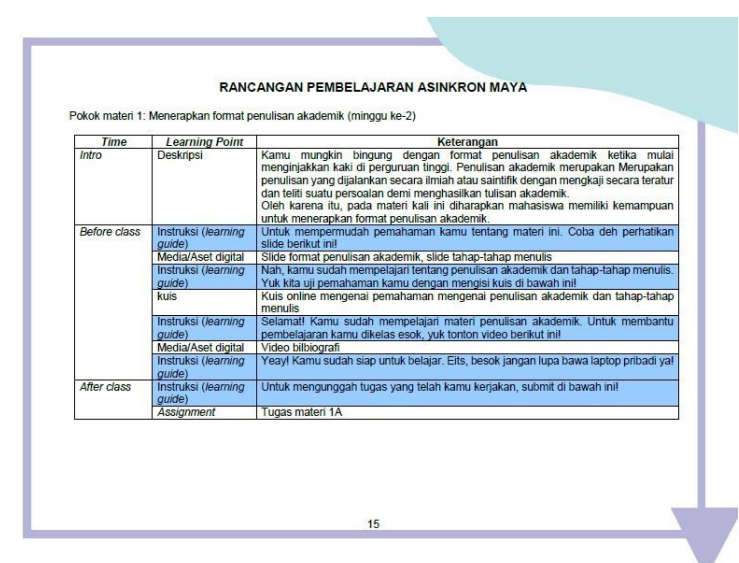

Gambar 14 Tampilan Rancangan Pembelajaran asinkron maya pada produk skripsi pengembangan Flipped Classroom

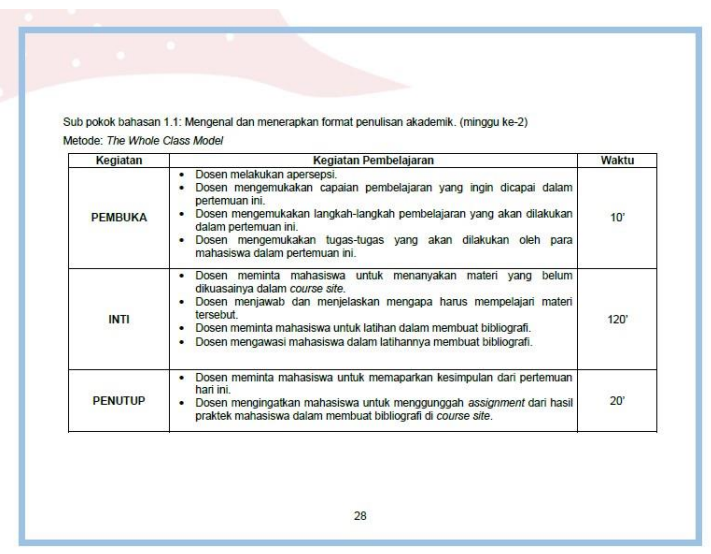

Gambar 15 Tampilan Rancangan Pembelajaran sinkron langsung pada produk skripsi pengembangan Flipped Classroom

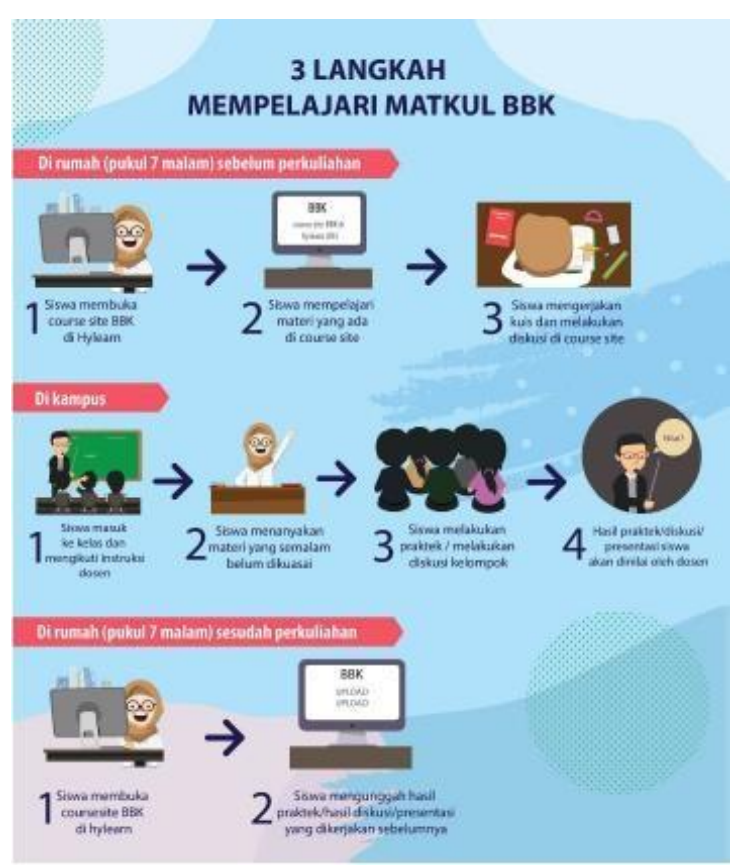

Gambar 16 Tampilan panduan pembelajaran pada produk skripsi pengembangan Flipped Classroom

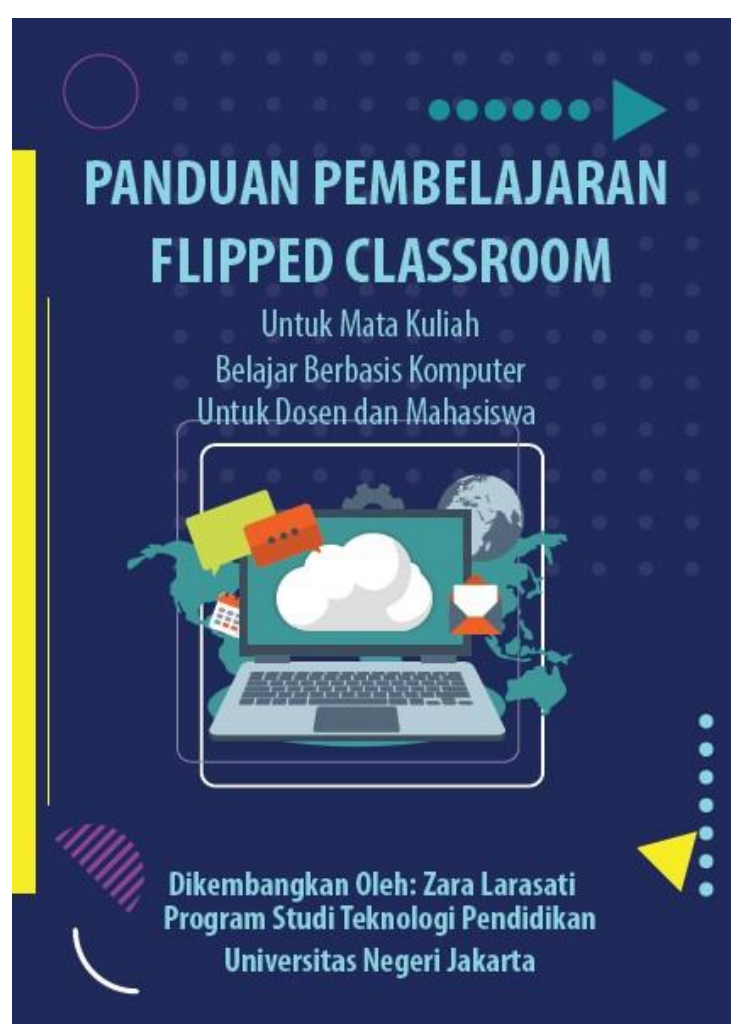

Gambar 17 Tampilan panduan pemanfaatan pada produk skripsi pengembangan Flipped Classroom 


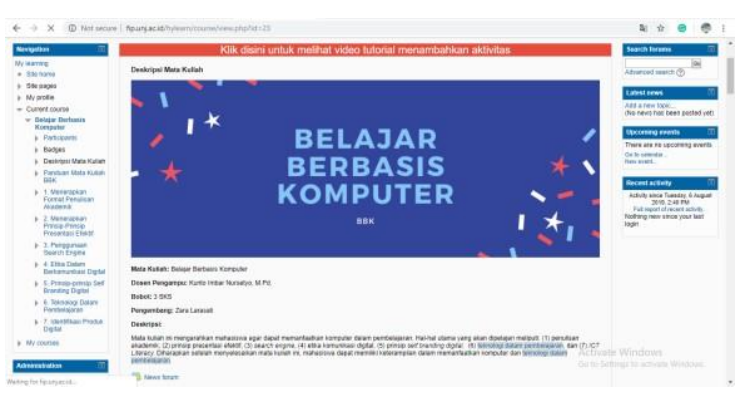

Gambar 18 Tampilan course site pada produk skripsi pengembangan Flipped Classroom

\section{SIMPULAN}

Produk yang dihasilkan dari pengembangan flipped classroom ini ialah perangkat pembelajaran dengan menggunakan model flipped classroom untuk mata kuliah belajar berbasis komputer. Produk ini dikemas ke dalam bentuk silabus perkuliahan, panduan pembelajaran, dan course site. Produk pembelajaran Flipped classroom ini dapat membantu pembelajaran mahasiswa dengan model pembelajarannya yang interaktif. Sehingga mahasiswa dapat termotivasi untuk belajar secara mandiri dan sesuai dengan gaya belajar setiap mahasiswa. Pengembangan flipped classroom ini dilaksanakan dengan menggunakan model pengembangan rapid prototype dimana terdiri dari lima langkah, yaitu: a) assess needs $\mathcal{E}$ analyse content, b) set objectives, c) construct prototype, d) utilize prototype, e) install \& maintain system.

Review ahli yang mengevaluasi produk pengembangan flipped classroom ini menyatakan bahwa produk flipped classroom ini memiliki kualitas yang sangat baik, secara ditinjau oleh ketiga ahli. Adapun hasil review yang dilaksanakan menunjukkan bahwa menurut ahli desain pembelajaran mendapatkan hasil sebesar 3,6 yang menunjukkan produk sudah sangat baik dan layak digunakan. Lalu hasil review menurut ahli materi mendapatkan hasil sebesar 3,8 yang menunjukkan produk sudah sangat baik dan layak digunakan. Lalu hasil review menurut ahli media mendapatkan hasil sebesar 3,3 yang menunjukkan produk sudah sangat baik dan layak digunakan.
Dengan demikian, berdasarkan prosedur tahapan mengembangkan flipped classroom serta uji coba yang telah dilaksanakan, maka dapat dinyatakan bahwa flipped classroom yang dikembangkan memiliki kualitas yang baik dan dapat digunakan oleh dosen pengampu mata kuliah BBK pada semester berikutnya.

\section{UCAPAN TERIMA KASIH}

Terima kasih saya ucapkan kepada dosen pembimbing, dosen-dosen yang terlibat, keluarga, teman-teman dan pihak-pihak yang telah mendukung selama proses penelitian berlangsung. Terimakasih atas semangat, masukan, canda, dan ssegala emosi yang dirasakan manusia dalam berlangsungnya penelitian ini.

\section{DAFTAR PUSTAKA}

Darmawan, D. (2014).

Pengembangan Elearning: Teori dan

Desain. Bandung: Remaja Rosdakarya.

Daryanto, \& Dwicahyono, A. (2014). Pengembangan Perangkat Pembelajaran (Silabus, RPP, PHB, Bahan Ajar). Yogyakarta: Gava Media.

Flipped classroom Field Guide. (2018, 12 12). Retrieved from https://tlc.uic.edu/files/2016/o2/Flippe d-Classroom-Field-Guide.pdf

FLIPPING THE CLASSROOM: WHAT WE KNOW AND WHAT WE DON'T Scientific Figure on ResearchGate. Available from: https://www.researchgate.net/figure/Bl ended-learning-models-StakerHorn2012_fig5_275535019 [accessed 22 Mar, 2019]. (n.d.).

Herala, A. V. (2015). Teaching programming with Flipped Classroom method: a study from two programming courses. In Proceedings of the 15th Koli Calling Conference on Computing Education Research. 
Nouri, J. (2016). The flipped classroom: for active, effective and increased learning-especially for low achievers. . International Journal of Educational Technology in Higher Education. Vol 13 (1) , 33-43.

Prawiradilaga, D. S. (2012). Wawasan Teknologi Pendidikan. Jakarta: Kencana.

Prensky, M. (2001). Digital Natives, Digital Immigrants. Retrieved from On the Horizon: http://s3.amazonaws.com

Straw, S., Quinlan, O., Herald, J., \& Walker, M. (2015). FLIPPED LEARNING. London: NFER \& Nesta.

Trilling, B., \& Fadel, C. (2009). 21st Century Skills: Learning for Life in Our Times. San Francisco: CA: John Wiley \& Sons.

Tripp, S. \&. (1990, January 7). Rapid Prototyping: An Alternative Instructional Design Strategy. Educational Technology, Research and Development. Retrieved from Rapid Prototyping: https://www.learntechlib.org/p/170553 I 